Revista Iberoamericana, Vol. LXXVIII, Núm. 241, Octubre-Diciembre 2012, 1001-1011

\title{
¿QUÉ RELATOS SON ÉSTOS? LOS DEBATES DE LA MEMORIA INDIVIDUALIZADA EN LOS TESTIMONIOS ARGENTINOS DE LA POSDICTADURA
}

\author{
POR \\ GRISELDA ZuFFI \\ Hood College \\ Solo un tiempo después, un tiempo de imprevisible duración, \\ una comunidad sale de las sombras para recuperarse \\ y recuperar lo que le pertenece. \\ Tununa Mercado
}

En el proceso de recuperación al que invita Tununa Mercado en Narrar después, están presentes las narraciones del pasado y los relatos de sobrevivientes que por distintos desplazamientos y silenciamientos históricos están surgiendo en las últimas décadas.

Es en los noventa que los discursos de la memoria tuvieron auge en el terreno mundial, sobre todo con la creación del Museo del Holocausto en 1993, cuyas resonancias sirvieron de prisma para entender otros genocidios. ${ }^{1} \mathrm{Si}$ bien la experiencia del Holocausto no puede servir de guía para comprender el devenir de las dictaduras, sí coincide en cuanto a las prácticas de la memoria que legitiman el espacio de lo subjetivo en la construcción de la historia reciente. A pesar del triunfo del "giro subjetivo", de las memorias individuales ligadas estrechamente al testimonio y de la valoración del testigo como fuente para contar la historia reciente, estas verdades se expulsan del análisis político y literario en los estudios de la memoria vigentes en la Argentina. Para esclarecer el uso de testimonio frente a otros géneros, cabría vincular éste a los trabajos de la memoria. ${ }^{2}$ Mi interés en este ensayo es dar cabida a los otros usos posibles del testimonio-no exclusivamente en el campo jurídico-como puesta en escena de registros y matices que ofrecen una crítica distinta de la práctica política. En este sentido, mi

1 Sobre el amalgama de los discursos de la memoria y del Holocausto, véase En busca del futuro perdido. Cultura y memoria en tiempos de globalización de Andreas Huyssen (13-40).

2 En el ensayo "Poetics of Remembering, the Poetics of Forgetting", Elzbieta Sklodowska se refiere al cruce de disciplinas en los estudios literarios cuyo enfoque no está en la construcción de la verdad. A pesar de que el proceso mnemónico es fundamental en la construcción del testimonio, es un campo que no ha tenido una mayor reflexión crítica (260). 
trabajo tiene como contrapunto el libro de Beatriz Sarlo, Tiempo pasado. Cultura de la memoria y giro subjetivo. Una discusión.

Los cruces de memoria e historia de vida están engarzados en los relatos testimoniales cuya pulsión es ser portadores de la verdad y por ello objeto cuestionable para el análisis disciplinario. ${ }^{3}$ He escogido tres testimonios de sobrevivientes de los Campos a fin de considerar el aporte de la memoria individual en la revisión y crítica de la política de los setenta y su vigencia en el presente: Memorias de una presa política (2006), Ese infierno. Conversaciones de cinco sobrevivientes de la ESMA(2001) y Una sola muerte numerosa (1997), escritos en los que se elabora desde la experiencia personal la vida en la cárcel y en los Campos en la Argentina durante y antes de la dictadura. A partir de su lectura, propongo otorgarle un sentido más amplio al testimonio, tan debatido en los estudios culturales y literarios, como posibilidad para el testigo de transmitir su experiencia y como vehículo indispensable para la preservación de la memoria.

Son varios los textos que, desde mediados de los noventa, retoman la militancia para configurar, desde fragmentos y recuerdos, ciertas experiencias del momento cuyo punto de reflexión más conflictivo ha sido el sobreviviente de los Campos. A partir de estos testimonios se ofrece un acercamiento más acorde con los trabajos que vienen realizándose en campo de la historia oral, que flexibilizan las fronteras disciplinarias para incorporar la memoria como objeto de estudio. Es en el área de las ciencias sociales que existe un intento de abordar críticamente la historia reciente desde el plano afectivo mediado por el recuerdo, cuestionando el pensamiento heredado de la historia racional y las formas en que se interpreta el mundo. Los ensayos compilados por Marina Franco y Florencia Levín en Historia reciente. Perspectivas y desafíos en un campo en construcción son una muestra del interés por comprender el pasado reciente y facilitar la recuperación de la experiencia en las escrituras propuestas -cuyos vestigios se pueden observar también en las novelas que recurren al recuerdo como eje de la narración-. ${ }^{4}$

En Memorias de una presa política, Ese infierno y Una sola muerte numerosa, las autoras tironean las voces de víctimas a través de sus relatos y su interpretación de las militancias. Surge en estas escrituras un tipo de relato que pone en tela de juicio el distanciamiento necesario para el análisis del pasado. Estas narraciones tensan la relación con la verdad, y por ello he tomado como contrapunto Tiempo pasado en el cual

3 Sobre este aspecto, véase El arte de no olvidar. Literatura testimonial en Chile, Argentina y Uruguay entre los 80 y los 90 de Nora Strejilevich. Los testigos no son sólo portadores de la "verdad" sino que hacen un cuidadoso trabajo "para unir su ser dividido entre zoé y cuidadano". Mediante este esfuerzo los sobrevivientes logran que el pasado no permanezca como un presente persecutorio (17).

4 A modo de ejemplo, en la más reciente publicación, podría mencionarse: Purgatorio de Tomás Eloy Martínez, La anunciación de María Negroni, El héroe sin nombre de Rodolfo Rabanal y Dos veces junio de Martín Kohan.

Revista Iberoamericana, Vol. LXXVIII, Núm. 241, Octubre-Diciembre 2012, 1001-1011
ISSN 0034-9631 (Impreso) 
se propone, a mi entender, la cancelación del testimonio a los efectos de una revisión histórica y su imposible entrada en el campo literario.

MEMORIAS DE UNA PRESA POLÍTICA (2006)

Beatriz Sarlo formula la siguiente pregunta: “¿Qué garantiza la memoria y la primera persona como captación de un sentido de experiencia?” (52) Guiada por la lectura, podría aventurar una posible respuesta. Cuando comencé a leer las primeras páginas de Graciela Loprete que narran su experiencia desde el día que llega al Hospital Penitenciario Central en el 75, mi primera reacción fue de fastidio: demasiado cuchicheo del lugar, de la gente y de la vida en el pabellón. Es un estilo etnográfico con atención al detalle de los orígenes, clases y dinámicas sociales, centrado en la marginalidad de las presas políticas. Loprete escribe un relato con las voces de otras prisioneras, los conflictos ideológicos entre las "independientes del rincón esquizofrénico" y las distintas organizaciones que comparten el espacio del encierro en el pabellón 49. Abría y cerraba el libro pensando en Graciela Loprete - ¿acaso la fuerza de la narración de la primera persona?-. Sabía de antemano que se había exilado en París en el 77 y que decidió quitarse la vida con barbitúricos en el 83, dejando tras sí un texto incompleto escrito en la cárcel y en el exilio y que sus viejas compañeras recuperan, enviando el manuscrito para su publicación. En la tapa vi una figura que evoca los setenta, una chica con un sweater tejido a mano, su pelo lacio con flequillo, raya al medio y una mirada abierta y sostenida al mundo. Me quedé con la foto, atraída por la imagen y cierto sentido de compasión. Pensé luego en el comentario de Pilar Calveiro en Política y/o violencia que critica la memoria individualizada y privada porque "pierde los sentidos políticos de la acción”, en la catarsis de los actos de memoria (16). El texto al que se refiere Calveiro es una cita de la tesis doctoral de Ludmila da Silva No habrá flores en la tumba del pasado en el cual hace referencia de la desilusión política de la esposa del militante desaparecido:

Ahí descubría la placa donde estaba mi marido y tantos compañeros. Me pareció espantoso. El problema es que tengo otra escuela política, entonces yo noto que hay una manera de hacer política con un contenido y que frente a la orfandad se borra toda continuidad política [...] Gente llorando horas. Yo creo que cualquiera de mis compañeros se levantan de la tumba y se agarran de los pelos [...] se quedan con el dolor pero no vi un solo activo, que reivindicase luchas en concreto y en acción. (17)

El cuestionamiento de ciertas "subjetividades" en los actos de memoria que podrían diluir el contenido político de la militancia de los setenta es un punto en común en los ensayos de Pilar Calveiro y Beatriz Sarlo. Esta digresión ante la lectura de Memorias de una presa política me permite reactivar un viejo mandato que dice NO: así no se lee

\footnotetext{
Revista Iberoamericana, Vol. LXXVIII, Núm. 241, Octubre-Diciembre 2012, 1001-1011 ISSN 0034-9631 (Impreso) 
la historia. La cancelación de la subjetividad como modo no apropiado para narrar el pasado en tiempos posrevolucionarios está arraigada, a mi entender, en una concepción de una estética no referencial, que Sarlo confirma al final de su ensayo, autorizando a Saer, Chejfec y Kohan, en pos de una política que debe ser relatada desde el distanciamiento intelectual ensayístico autorizando, por supuesto, a Pilar Calveiro.

¿Qué relatos son éstos? ¿Cómo hacer una lectura que sostenga el contenido político de la lucha sindical, las estrategias y prácticas de las distintas militancias? ¿Cómo dar cuenta del deseo de cambio en las relaciones de clase, en las relaciones sexuales, y en los proyectos sociales de un mundo igualitario? Los familiares y amigos de "desaparecidos" y los sobrevivientes de los Campos traen al presente aspectos íntimos de la memoria ya que se resisten a dejarlos en el olvido. Memorias de una presa política, por ejemplo, no es sólo de Graciela Loprete, como aclara María Moreno en el epílogo, sino de las compañeras que, en calidad de legataria, entregaron el texto para su publicación.

En Memorias de una presa política la autora posa la mirada sobre lo que significó ser militante, sobre lo que resta por hacer, "abandonar el espíritu de secta” (48), pensar el trabajo como centro de las organizaciones políticas, salir de la tirantez y del secretismo político entre las compañeras. En el aislamiento se produce en Loprete una nueva fantasía más poderosa que el afuera donde ella se anima a "encanutar el relato” (79). Su preocupación está enmarcada en el "adentro” y es allí donde reflexiona cómo eliminar las desigualdades de clase o de ideología. Las miradas de los otros persiste, como la de Blanca que dice: "vos que sos leída y yo muy ignorante" (118). Las diferencias entre "nosotras" resultan muy molestas para Loprete que trata de generar redes de comprensión para quienes están en la misma vereda. Se va espesando el encierro con el traspaso de una política sostenida en secreto en cada grupo (139).

Este libro está escrito en el exilio y el punto de mira es comprender la historia vivida en la militancia. Es un indagar a través de la conversación con las compañeras que va encontrando un sentido a la experiencia militante. En el capítulo titulado “César”, Loprete, estudiante de sociología y ex militante de Vanguardia Comunista, se revela como una persona signada por la ambigüedad y cuenta su llegada a la cárcel con una dosis de humor. La vida cotidiana en el encierro le permite diferenciar a la autora lo importante de lo trivial, y ciertas cosas se vuelven risibles. Se va diluyendo el peso de la heroicidad:

\begin{abstract}
Aterricé en la cárcel cuando había abandonado la militancia política. Había sido una cristiana consecuente, después una intelectual culpabilizada y más tarde una militante sin convicción. Moralista entre los intelectuales “puros” y escéptica entre los militantes decididos. Lo único que me faltaba era ser presa política por amistad. (79)
\end{abstract}

En el Hospital Penitenciario Central hay fuertes y débiles, operarias que habían sido abandonadas por su organización después de la caída, hay quienes se pierden en

Revista Iberoamericana, Vol. LXXVIII, Núm. 241, Octubre-Diciembre 2012, 1001-1011
ISSN 0034-9631 (Impreso) 
el mutismo y la locura o aquellas que se juntan por sus mismas posturas ideológicas.

Como lo había manifestado de manera incipiente Marta Diana en su pionero trabajo, Mujeres guerrilleras (1996), los testimonios escritos por mujeres ponen de relieve aspectos de la vida militante, hasta entonces ausentes u opacados. Temas como: las relaciones amorosas en todas sus vertientes, la vida cotidiana y la sexualidad. Sobre todo se ponen en escena las vacilaciones y las contradicciones que la militancia les planteaba a las mujeres. Este giro permite pensar ese mundo de la militancia como un estado de vida más complejo y diverso que entra en discusión con otras narraciones que solían presentarlo casi sin fisuras.

ESE INFIERNO (2001)

"De denuncia tenemos bastante en Argentina. Hay que contar el pasado de otro modo", dice Elisa Tokar, sobreviente de la ESMA. ${ }^{5}$ En Ese infierno. Conversaciones de cinco mujeres sobrevivientes de la ESMA (2001) Munú Actís, Cristina Aldini, Liliana Gardella, Miriam Lewin y Elisa Tokar toman la iniciativa de contar lo que significó sobrevivir la ESMA. Para ello, eligen el modo de la conversación. El armado del libro es el resultado de un cuidadoso grabar y des-grabar que las sobrevivientes realizaron junto a la editora. Ellas eligieron los epígrafes, reunieron los temas, optaron por abandonar el ordenamiento cronológico con el cual iniciaron las conversaciones. La intención se anuncia en el prólogo: "[...] salir del amparo del lenguaje estructurado, del testimonio ante un juez o un organismo de derechos humanos para describir la vida diario en el Campo" (13). Pero además hay un deseo de encontrar otro lenguaje que explique su experiencia sin el tono denunciante. Eligen la conversación, un modo más íntimo para recordar lo vivido. Sus recuerdos giran en torno a preguntas que ellas mismas intentan responder. Los capítulos se organizan de modo temático: 1. Los días previos y el secuestro; 2. Detenidas-desaparecidas; 3. Día a día en cautiverio; 4. Torturadores, 5. Una excursión al mundo exterior; 6. Bebés bajo custodia; 7.Liberación y después; 8. El Holocausto judío; y 9. Presos políticos. Este ordenamiento surgió de la necesidad de comunicar una experiencia traumática de modo que fuera legible para los demás.

Las cinco sobrevivientes venían de distintas agrupaciones políticas y si bien todas compartieron la vida diaria en cautiverio, no todas tuvieron la misma actitud frente a la militancia, no todas vivieron del mismo modo los límites de la simulación, y no todas hablan hoy de víctimas y victimarios o de las traiciones. Las reflexiones sobre la derrota muestran los distintos modos en que atravesaron ese camino y siguen indagando sobre los sentimientos contradictorios del presente. ¿Qué significó perder un proyecto político de los setenta? La conversación permite seguir las voces de cada

5 Entrevista personal con Elisa Tokar y Liliana Gardella, julio 2002.

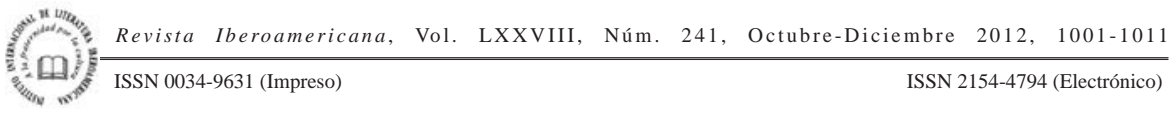


una distanciándose de la exigencia moral de ser fieles a los hechos. La charla es fiel al recuerdo y reconstruimos la historia vivida, la faz humana, y las "pequeñas agachadas" que hacían para seguir viviendo.

Después de haber vivido un proyecto tan movilizador desde lo colectivo, recuperar la normalidad parece casi imposible. Para Elisa Tokar, surgió una Elisa más light, más liviana, a la otra, la mataron (65). Para Liliana Gardella, la pérdida de proyecto después del secuestro implicó un cambio profundo del ser y del modo de relacionarse con las personas: "Es muy grande el esfuerzo para encontrarle sentido a lo que hago, para hallar el punto ético, para darles espacio a los afectos, es un esfuerzo tremendo porque carezco de naturalidad. No te matan el cuerpo pero esto también es morir” (65).

Ese infierno describe el plano afectivo de las relaciones entre presas y torturadores, habla de la culpa, el terror, la terrible anormalidad que impuso la ESMA. No se trata de un recordar lastimoso de cinco mujeres víctimas, sino de un trabajo de quienes se arriesgan a poner el cuerpo en una escritura que recupera la experiencia personal y colectiva, para re-ubicarnos en un presente que nos queda por construir con las muertes y los sobrevivientes muy de cerca.

Una sola muerte numerosa $(1997,2006)$ de Nora Strejilevich es un texto híbrido que entreteje el documento y la ficción. Sigue las huellas del “tiempo vivo” del desaparecido y al narrar su vida desdice lo que el ejército, la marina, los torturadores y diversos sectores de la sociedad dicen o creen que son: subversivos con armas. La autora plantea que las ideologías, si las había, eran juveniles, rebeldes, utópicas: el heroísmo de la militancia no tiene cabida en la narración. Strejilevich, detenida desaparecida en el 77, opta por contar lo sucedido desde el día de su secuestro entrando por los resquicios de lo que debe olvidar. Los lugares de sombra, la vida en el campo clandestino Club Atlético, y el afuera. Las voces de padres, madres, hijos, primos y novias se van uniendo. La experiencia de unos y de otros se va atravesando como las geografías que también se superponen. No hay un territorio nacional ni transnacional que pueda devolver la identidad, el sentido de pertenencia a una comunidad. La narradora junta los restos de una historia como una arqueóloga forense que revisa los despojos humanos en las fosas marcadas NN, sólo que en las ruinas todavía hay seres vivos que le cuentan un pasado de horror. Nunca se puede contar el hecho tal y como sucedió. La narradora revive su secuestro como lo recuerda. No se trata sólo de la desaparición sino del borramiento de la identidad, individual y colectiva. La secuestrada, el día que la llevan, es la rubia, la judía, la nieta de una rusa inmigrante. Pierde su nombre en el campo. Ahora es K-48, pero también pierde su identidad cuando sale al exilio. La vivencia en el Campo exige el olvido: el día que la llevan se suma a otro día, el que lo llevan a él, a Gerardo, o el día que la torturan o el mismo día que ella escucha y reconoce la voz de su hermano bajo tortura. Escribir sobre un desaparecido, para un sobreviviente, es de algún modo recuperar lo que le fue quitado y sólo se puede aproximar a ese pasado con preguntas:"¿Acaso

Revista Iberoamericana, Vol. LXXVIII, Núm. 241, Octubre-Diciembre 2012, 1001-1011
ISSN 0034-9631 (Impreso) 
fue así, Gerardo?” (120) Así reconstruye un pasado que vuelve en forma de recuerdo incierto. Los responsables de la desaparición y la muerte de su hermano, su novia, y de otros familiares también aparecen en el texto: se insertan como mensajeros del odio, como los comunicados del ejército cuyas sentencias, asesinatos y mentiras se registran en un tono irónico. Lo que quedó de ese lenguaje se contrapone a la experiencia y voz humana de muchas víctimas. El secuestro vivido marca un antes y después "no todos los días uno abre la puerta para que un ciclón desmantele cuatro habitaciones y destroce el pasado y arranque las manecillas del reloj” (15). Esta experiencia se repite palabra por palabra al narrar el secuestro y desaparición de Gerardo.

Strejilevich recurre a la ironía, el humor, la burla de los sistemas legales, el aparato burocrático, incluso de los organismos de derechos humanos. Las "pruebas" que necesita para presentar ante las autoridades para recibir indemnización, las "pruebas" que tiene que ofrecer ante la embajada para poder salir del país, la "prueba” para mostrar el grado de daño permanente o parcial de un órgano vital en su propio cuerpo, mientras que el "Club Atlético", campo clandestino donde murieron más de 1,500 personas, es una ruina apenas visible como sitio de la memoria bajo las columnas de una autopista sobre la Avenida Paseo Colón.

\section{DEL TESTIMONIO AL ENSAYO}

Si la memoria, como sugiere Vezzetti, "excede la denuncia de los crímenes en la medida en que la búsqueda de la verdad, de cara a la sociedad, enfrenta algo distinto de la culpabilidad de los criminales", los testimonios ofrecidos registran la memoria a través del plano afectivo para comprender el pasado y amplían los "usos del testimonio" más allá del plano jurídico (Pasado 40). Si bien no encuentran un lugar preciso dentro de la crítica cultural presente, los testimonios de sobrevivientes dan lugar a una autocrítica de la militancia y su participación en la política de los setenta. El modo testimonial no descarta ni desplaza la argumentación ensayística. No entiendo-y lo digo con ingenuidad literaria y en primera persona-: por qué hay que favorecer la argumentación sobre la experiencia, así como no puedo entender por qué se debe subordinar la experiencia al saber. Supongo que aquí es donde entra en discusión el cuadro letrado que presenta Sarlo en los capítulos finales de su ensayo. Por un lado, se apunta el desgaste que produce la memoria como mercancía, anulando el significado del recuerdo para elaborar sobre el pasado de la dictadura. Ricardo Forster y Héctor Schmucler dedican varios ensayos en Pensamiento de los confines sobre el riesgo de la memoria, en particular, a través de la mass media; hablan de la saturación, oportunismo o cansancio que producen los medios. Por otro lado, en el espacio académico del Norte también se debate el riesgo del testimonio de convertirse en un momento "post" porque la "urgencia” del testimonio,

\footnotetext{
Revista Iberoamericana, Vol. LXXVIII, Núm. 241, Octubre-Diciembre 2012, 1001-1011 ISSN 0034-9631 (Impreso)

ISSN 2154-4794 (Electrónico)
} 
el momento como tal fue. ${ }^{6}$ (En este sentido, el ensayo de Beatriz Sarlo agrega otra incapacidad al testimonio de hacer una valoración de "lo político", en este caso, por ser demasiado humano y posmoderno).

Una revisión del testimonio -dentro de los módulos de la posmodernidad y de la deconstrucción-remueve del género uno de sus elementos centrales como "ser portadores de la verdad” pero deja al testimonio en un "limbo interpretativo”. La problemática de género vuelve a actualizarse en Estados Unidos después del debate Rigoberta Menchú y David Stoll, en el que el antropólogo cuestiona la verdad del testimonio de Rigoberto Menchú, en base a entrevistas que realiza en Guatemala. Como resultante de ese debate, en la colección de ensayos de Arturo Arias The Rigoberta Menchu Controversy, Mary Louise Pratt propone un marco teórico más elaborado para el género a fin de evitar otras normas interpretativas (legales) que no corresponden a la ética del testimonio. En cuanto al "limbo interpretativo” Pratt y Sarlo estarían en común acuerdo por distintas razones. Pensar la historia requiere para la crítica argentina un regreso a lo político, pero cabría preguntarse de qué modo entra lo político después del silenciamiento que implicó la dictadura y que aún repercute en el tejido social argentino -cabría recordar el lúcido análisis de Sarlo en 1985, “Literatura y política”, donde define la producción literaria como búsqueda de sentidos de una historia obturada-.

"No hay lugar para reconstrucciones épicas ni para la exaltación de conductas heroicas”, dice Hugo Vezzeti en Presente y pasado (13). Bien, pero tampoco parece que se le dé lugar a la voz del testigo. Se produce una incomodidad sobre todo cuando opera en los textos una vena literaria. Si leí bien el ensayo de Sarlo, Tiempo pasado cancela un posible futuro para las narraciones escritas desde la subjetividad de la experiencia porque los testimonios, como por ejemplo, La escuelita de Alicia Partnoy que Sarlo analiza, fracasan como instrumentos de reflexión política. Uno de los textos estudiados en las universidades de los Estados Unidos y que fue crucial en la exposición de los efectos del terrorismo de Estado en los ochenta fue The Little School. Tales of Disappearances deAlicia Partnoy (recientemente editada en Argentina como La escuelita: relatos testimoniales). En las páginas que le dedica Sarlo reflexiona sobre las carencias ideológicas ¿literarias? del texto. Lo que resalta del texto son los detalles insignificantes. Esta escritura testimonial, según Sarlo, no ofrece valor crítico. Por el contrario, obstruiría la interpretación crítica y vaciaría el entendimiento político del pasado, un ejemplo más de la "historia ausente”. Sin embargo, no queda claro en su análisis cuáles son los otros usos públicos del testimonio que debilitan la memoria y el análisis histórico. Supongo

${ }^{6}$ A mediados de los noventa, aparecieron varios estudios críticos en torno al testimonio. Véanse los ensayos reunidos en Georg Gugelberger, ed. The Real Thing y los del crítico brasileño Idelber Avelar, en su conocido estudio Alegorías de la derrota. La ficción posdictatorial y el trabajo del duelo, en particular, "Genealogía de la derrota".

Revista Iberoamericana, Vol. LXXVIII, Núm. 241, Octubre-Diciembre 2012, 1001-1011
ISSN 0034-9631 (Impreso) 
que el "literario". Si en los ochenta Sarlo proponía que la producción literaria era un modo de "pensar la historia" en un momento de máxima fragmentación de la experiencia social y abrió el espacio literario para que entrara de lleno la escritura de la historia en la narrativa de la posdictadura, parece que en tiempos neoliberales tomara nuevamente el distanciamiento intelectual y teórico ante los convulsionados sesenta a fin de poner límites a los excesos de la memoria privada.

La descarga emocional o la catarsis que produce la escritura en primera persona no es el motor de la historia ni el problema entre memoria e historia que se plantea en estos textos personales sino el sostén de la verdad y los problemas que esto atañe en la construcción del pasado desde la memoria personal y privada. Sobre este punto hay mucho que está en sombras, sobre la relación entre testimonio y memoria y el sentido de verdad que aporta el testigo. "Se ha impuesto el giro subjetivo", sostiene Beatriz Sarlo, casi como un desafío, en el comienzo de su ensayo. Reconoce la importancia de la primera persona para reconstruir la memoria del pasado trágico pero según argumenta el testimonio es irrefutable y poco sirve a la reflexión y a la autocrítica. Si bien hay una producción testimonial considerable, la evaluación crítica en torno a este vínculo políticoliterario de larga tradición en la Argentina, se ha vuelto escéptica y autoritaria. Quizás en los ochenta la teoría literaria seguía los pasos de la crítica francesa y el testimonio no sólo se eclipsó como género por la censura de la dictadura sino porque entraba en crisis la representación mimética de la realidad, y en esto el testimonio pierde terreno. Si en los setenta el testimonio funcionó como una de las formas más insistentes del recuerdo individual y colectivo y de la escritura de denuncia para superar el olvido de la historia, en los ochenta se quiebra la versión realista como forma de representación. La ficción histórica -heredera del boom- viene a llenar un vacío donde se fragua el discurso testimonial socavando los criterios de veracidad y referencialidad inherentes al mismo. Desde los noventa y sobre todo a partir del posicionamiento político de los actores sociales de los setenta, se revisa la función de la militancia en la historia argentina. Además de los textos testimoniales, fieles en heroicidad en muchos casos a la de los/las protagonistas, aparece una forma de narrar que intenta borrar la construcción heroica tan difundida en los medios. Con excepción de Recuerdo de la muerte de Miguel Bonasso que está dentro de la tradición policial/testimonial de Walsh, o los testimonios orales transcriptos como Pájaros sin luz o La voluntad, los más “literarios” han tenido poca difusión.

El testimonio de denuncia se ha desplazado hacia una verdad recordada. En tiempos posrevolucionarios la reflexión sobre el pasado no tiene por qué ser nostálgica, ni ajustarse a un determinado modelo histórico pero puede favorecer la reflexión crítica desde una base abierta, plural, donde la memoria íntima tenga cabida.

\footnotetext{
Revista Iberoamericana, Vol. LXXVIII, Núm. 241, Octubre-Diciembre 2012, 1001-1011 ISSN 0034-9631 (Impreso) 
Actis, Munú, Cristina Aldini, Liliana Gardella, Miriam Lewin y Elisa Tokar. Ese infierno.Conversaciones de cinco mujeres sobrevivientes de la ESMA. Buenos Aires: Sudamericana, 2001.

Arias, Arturo. The Rigoberta Menchú Controversy. Minneapolis: U of Minnesota P, 2002. Avelar, Idelber. The Untimely Present. Postdictatorial Latin Amreican Fiction and the Task of Mourning. Durham: Duke U P, 1999.

Beverley, John. On Testimonio. The Politics of Truth. Minneapolis: U of Minnesota P, 2004.

Calveiro, Pilar. Política y/o violencia. Una aproximación a la guerrilla de los años 70. Buenos Aires: Norma, 2005.

Casullo, Nicolás. "Una historia de la memoria para las muertes de la Argentina". Pensamiento de los Confines 9/10 (2001): 9-47.

Forster, Ricardo. “Las almas de los muertos”. Confines 4 (1997): 35.

Franco, Marina y Florencia Levín, comps. Historia reciente perspectivas y desafíos para un campo en construcción. Buenos Aires: Paidós, 2007.

Gillespie, Richard. Soldiers of Perón: argentina's Montoneros. Oxford: Clarendon P, 1982.

Huyssen, Andreas. En busca del futuro perdido. Cultura y memoria en tiempos de globalización. México D.F.: FCE, 2002.

Loprete, Graciela. Memorias de una presa política 1975-1979. Buenos Aires: Norma, 2006.

Mercado, Tununa. Narrar después. Rosario: Beatriz Viterbo, 2003.

Partnoy, Alicia. La escuelita: Relatos testimoniales. Buenos Aires: La Bohemia, 2006.

Reati, Fernando y Adriana Bergero, comps. Memoria colectiva y políticas de olvido. Argentina y Uruguay, 1970-1990. Rosario: Beatriz Viterbo, 1997.

Reati, Fernando. "Historias de amor de ex-presas políticas". Ínsula. Revista de Letras y Ciencias Humanas 711 (2006): 24-30.

Sarlo, Beatriz. Tiempo pasado. Cultura de la memoria y giro subjetivo. Una discusión. Buenos Aires: Siglo XXI, 2005.

Schmucler, Héctor. "Las exigencias de la memoria”. Punto de vista 68 (2000): 5-9.

Sklodowska, Elzbieta. "Poetics of Remembering, the Poetics of Forgetting." The Rigoberta Menchú Controversy. Arturo Arias, ed. Minneapolis: U of Minnesota P, 2001.

Strejilevich, Nora. El arte de no olvidar: literatura testimonial en Chile, Argentina y Uruguay entre los 80 y 90. Buenos Aires: Catálogos, 2006. Una sola muerte numerosa. 2 ed. Córdoba: Alción, 2006.

Terán, Oscar. “Tiempos de memoria”. Punto de vista 68 (2000): 10-12.

Valenzuela, Luisa. Peligrosas palabras. Buenos Aires: Editorial Temas, 2001.

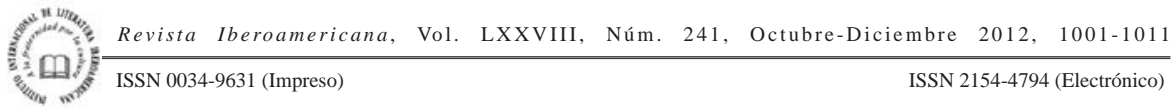


Vezzetti, Hugo. "Representaciones de los campos de concentración en la Argentina". Punto de vista 68 (2000): 13-17.

Pasado y presente. Guerra, dictadura y sociedad en la Argentina. Buenos Aires: Siglo XXI, 2002.

Revista Iberoamericana, Vol. LXXVIII, Núm. 241, Octubre-Diciembre 2012, 1001-1011 ISSN 0034-9631 (Impreso) ISSN 2154-4794 (Electrónico) 
